\title{
Parametric Design and Experimental Study for Weak Area Structure of Circle Composite Fragile Cover
}

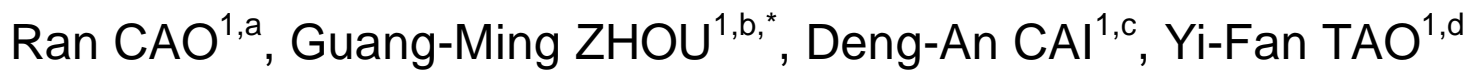 \\ ${ }^{1}$ State Key Laboratory of Mechanics and Control of Mechanical Structures, Nanjing University of \\ Aeronautics and Astronautics, Nanjing 210016, China \\ accaoran900521@sina.com, bzhougm@nuaa.edi.cn, 'cda@nuaa.edu.cn, ${ }^{\mathrm{c}}$ ivansgotostudy@163.com \\ ${ }^{*}$ Corresponding author
}

Keywords: Composite Fragile Cover, Weak Area Structure, Numerical Simulation, Structure Parameters, Strength Envelopes, Parametric Design.

\begin{abstract}
A Parametric design method for weak area structure of circle composite fragile cover was proposed by analysis of mechanical properties of circle composite fragile cover and weak area structure, which was confirmed by rush experiments. Firstly, boundary conditions of the weak area structure were determined by numerical simulation for circle composite fragile cover. Material parameters of weak area structure were simplified by classical lamination theory. Secondly, the strength of weak area structure was determined by numerical simulation under eleven different ratios of bending-stretching coupling load, and the strength envelopes were developed subsequently. Then the effect of thickness and length of lapped fiber layers on the strength of weak structure were discussed. According to maximum principle stress rule, the curves of strength and structure parameters versus different bending-stretching coupling load were presented and parametric design method of the weak structure was proposed. Lastly, two types of circle composite fragile cover was made for rush experiment. The results show: 1) Glue layer undertakes the tensile load, and loped glass cloth undertakes the sheer load. 2) The tensile strength is influenced by the thickness of lapped layers, while the shear strength is mainly affected by the length of glass cloth. 3) The theoretical results are in close agreement with the experimental data and the mean error is about $11 \%$, which proves the feasibility of the proposed parametric design method.
\end{abstract}

\section{Introduction}

With the development of missile weapons, the missile launchers have become more and more important and its performance directly affects the operational performance of missile weapons. Missile launching cover has become an essential part of missile launchers which can protect missile by maintaining internal pressure.

Mechanical open system and explosion open system have been used in missile launchers [1-4], but they are heavy, complex and slow to response so that these systems do not meet the requirements of fast combat.

Composite material with high strength ratio and modules ratio, corrosion resistance property [5-7], excellent designable and easily molding property has been used to make missile launching cover $[8,9]$. In order to meet the requirements of sealing and failure under given conditions, the weak area with some strength should be made on composite fragile cover.

For the tensile strength of longitudinal fibers are higher than lateral fibers, a kind of weak area structure of American Harpoon missile launchers cover[10] has been made by prefabricating vertical and horizontal defects in single layer. When launching, the defect of weak area is damaged by warhead.

The cover of Russian S-300 missile vertical launching system and SA-N-6 "Cardiff" missile vertical launching system uses of special composite materials, and weak area is constituted by some regular pre-groove. When launching, the airflow acts on the cover, which leads to the failure of cover caused by the stress concentration of pre-groove.

ZHOU Guang-ming[11,12] has been developed an integrated frangible composite diaphragm Cover. This paper proposes a way to control the strength of the weak area by changing the number of inside and outside lapped fiber layers between separated cover and framework.

Weak area structure is an important factor which affects the mechanical performance of the fragile cover[13], and circle missile launching cover is widely used nowadays. So the study and design for weak 
area structure of circle composite fragile cover are more important. In this paper, bonding structure with double-sided lapped fiber layer is calculated under eleven different ratios of bending-stretching coupling load. Then the effects of Parameters of weak structure were discussed, and the strength envelopes were developed subsequently. According to the maximum principle stress rule, a parametric design method for weak area structure is developed, and two type covers are designed. Parametric design method is feasible by the experiments.

\section{Micro Structure of Weak Area}

Weak area of circle composite fragile cover is a bonding structure with double-sided lapped fiber layer, which is between separated cover and framework. The structure of weak area is shown in Fig 1. At air-tight condition, the weak area can maintain internal pressure. At break condition, the lapped fiber layer separates from framework, and weak area is failure. Failure of weak area is due to lapped fiber layer separates from framework, so the mechanical performance of inferior part of bonding structure is an important factor which affects the strength of weak area. The length of lapped fiber layer (l) and the thickness $(t)$ are important parameters. The length of weak area structure: $L 0=12 \mathrm{~mm}$, the width of weak area structure: $b=4 \mathrm{~mm}$, the thickness of weak area structure: $h=4 \mathrm{~mm}$, the thickness of glue layer is $0.1 \mathrm{~mm}$.

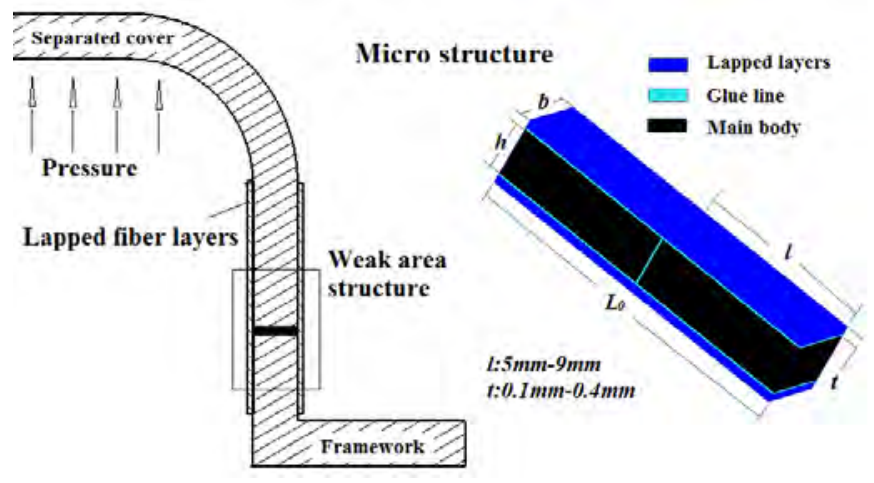

Fig. 1 Schematic Diagram of Weak Aero Structure

According to the classical lamination theory, the composite layers can be equivalent to single laminate. The cover uses $(0 / 90)$ ply way, and the lapped fiber layers use $0.1 \mathrm{~mm}$ glass fiber Twill with same pal way like the cover. The cover and lapped fiber layers can be calculated by:

$$
E_{11}=E_{22}=1 / 2\left[V_{f} E_{f 1}+\left(1-V_{f}\right) E_{m}\right]
$$

Where $E_{11}$ and $E_{22}$ are obtained by the experiments, $V_{\mathrm{f}}$ is calculated by elastic modulus.

$$
E_{33}=E_{m} E_{f 2} /\left(V_{f} E_{f 2}+\left(1-V_{f}\right) E_{m}\right)
$$

According to an empirical formula and average volume method, the shear modulus $G_{11}$ and $G_{22}$ are calculated by:

$$
G_{23}=G_{13}=2 G_{m} G_{f 2} /\left[G_{m} V_{f}+G_{f 2}\left(2-V_{f}\right)\right]+G m /\left[1-V_{f}\left(1-G_{m} / G_{f 23}\right)\right]
$$

Poisson's ratio can be expressed by:

$$
\mu_{23}=\mu_{13}=V_{f} v_{f 23}+\left(2 v_{m}-v_{21}\right)
$$

Where $V_{f}$ is fiber volume fraction, $E_{m}$ is matrix elastic modulus, $E_{f 1}$ is elastic modulus of fiber length direction, $E_{f 2}$ is elastic modulus of fiber lateral direction, $v_{f 12}$ and $v_{f 23}$ are Poisson's ratio of fibers, $v_{m}$ is matrix Poisson's ratio, $G_{f 12}$ and $G_{f 23}$ are shear modulus of fiber, $G_{m}$ is matrix shear modulus. The material properties are presented in Table 1.

Based on the formulas which are mentioned above, the parameters of cover and lapped fiber layer are proposed, and the results are presented in Table 2. 
Tab. 1 Material Properties

\begin{tabular}{ccc}
\hline Mechanical Properties & Epoxy Resin & Glass Fiber \\
\hline$E_{f 1} / \mathrm{GPa}$ & 3.5 & 73 \\
$E_{f 2}, E_{f 3} / \mathrm{GPa}$ & 3.5 & 3.5 \\
$G_{f 12}, G_{f 13} / \mathrm{GPa}$ & 1.3 & 30 \\
$G_{f 23} \mathrm{GPa}$ & 1.3 & 30 \\
$v_{f 12} v_{f 13}$ & 0.35 & 0.22 \\
$v_{f 23}$ & 0.35 & 0.22 \\
\hline
\end{tabular}

Tab. 2 Material Parameters of Weak Aero Structure

\begin{tabular}{cccccc}
\hline $\begin{array}{c}\text { Mechanical } \\
\text { Properties }\end{array}$ & Composite/MPa & $\begin{array}{c}\text { Mechanical } \\
\text { Properties }\end{array}$ & Composite/MPa & $\begin{array}{c}\text { Mechanical } \\
\text { Properties }\end{array}$ & Composite \\
\hline$\overline{E_{11}}$ & 21500 & $\overline{G_{12}}$ & 3420 & $\overline{\mu_{23}}$ & 0.23 \\
$\overline{E_{22}}$ & 21500 & $\overline{G_{13}}$ & 1060 & $\overline{\mu_{12}}$ & 0.11 \\
$\overline{E_{33}}$ & 5550 & $\overline{G_{23}}$ & 1060 & $\overline{\mu_{13}}$ & 0.23 \\
\hline
\end{tabular}

\section{The Strength Criterion}

\section{Stress-strain Relationship}

In the course of cover carrying, the hoop stress $\left(\sigma_{\mathrm{y}}\right)$ is much less than the radial stress $\left(\sigma_{\mathrm{x}}\right)$ and the horizontal stress $\left(\sigma_{\mathrm{z}}\right)$ of weak area structure, therefore, the weak area structure is two dimensional stress state. The strength of weak area structure is expressed by average longitudinal strain and the average shear strain on the XZ plane. Schematic diagram of structural deformation is shown in Fig 2 . Where $z_{2}$ is average displacement at $\mathrm{Z}$ direction, $x_{2}$ is average displacement at $\mathrm{X}$ direction.

The stress-strain relationship of $Z$ direction and shear stress-strain are expressed by:

$$
\begin{aligned}
& \varepsilon_{z}=\left(z_{1}-z_{2}\right) / L_{0}, \gamma_{x z}=\left(x_{1}-x_{2}\right) / L_{0} \\
& \sigma_{z}=\mathrm{E}_{11} \varepsilon_{\mathrm{z}} \quad \tau_{\mathrm{xz}}=\mathrm{G}_{13} \gamma_{x z}
\end{aligned}
$$

According to the theory of material mechanics, the maximum principal stress is calculated by:

$$
\left.\begin{array}{c}
\sigma_{\max } \\
\sigma_{\min }
\end{array}\right\}=\frac{\sigma_{\mathrm{x}}+\sigma_{\mathrm{z}}}{2} \pm \sqrt{\left(\frac{\sigma_{\mathrm{x}}-\sigma_{\mathrm{z}}}{2}\right)^{2}+\tau_{\mathrm{xz}}^{2}}
$$

\section{Stress-strain Relationship}

Within the range of given parameters, the failure of weak area structure is lapped fiber layer separates form framework. In this paper, the ideal failure is fracture of glue line, so the maximum principal stress[13] is used as strength check of glue line.

$$
\sigma_{\text {max }} \leq \sigma_{\mathrm{b}}
$$

\section{Finite Element Models}

\section{Finite Element Analysis of Fragile Cover}

In order to ensure the boundary conditions of the weak area structure more accurately, the finite element analysis should be done first. The two-dimensional discretization shell finite element is used to meshing the cover, and the mesh of weak area and corner of fragile cover is refined. The materials of weak area are same with the cover. The analysis results are shown in Fig 3, which demonstrates: the weak area structure bears the tensile load and the bending load. 
As to the boundary conditions of the weak area structure, the hoop constraints should be ignored. Parameter variable is the length and the thickness of lapped fiber layer, the height of weak area structure model keeps invariant. The parameter variable is changed by adjusting the ratio of the upper and lower joint portion.

The loading surface of the weak area structure is the upper end face, and the displacement loading finite element method is used to finite element analysis. The bending-stretching coupling load is acted on the upper end face, and the lower end face is clamped.

The radio of bending-stretching coupling load of the weak area structure is changed with the increase of uniform pressure on the cover. In order to fitting strength envelope of weak area structure, in this paper, calculate eleven different ratios of bending-stretching coupling load conditions is performed. The ratios are presented by Table 3 .

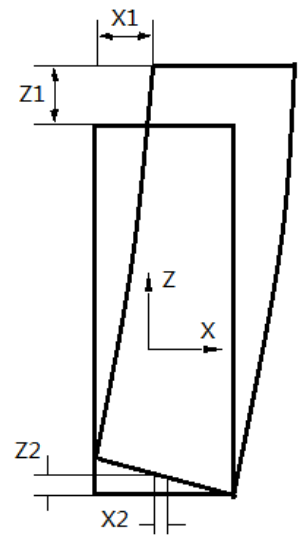

Fig. 2 Schematic Diagram Of Structural Deformation


Fig. 3 Cloud picture of Z-direction and Radial Displacementin Local Coordinate

Tab. 3 Different Tension-Bending Coupling Load

\begin{tabular}{ccc}
\hline Ratio of Load & Z-Direction Displacements $(\mathrm{z} 1) / \mathrm{mm}$ & $X$-Direction Displacements $(\mathrm{x} 1) / \mathrm{mm}$ \\
\hline $10: 0$ & 0.01 & 0 \\
$9: 1$ & 0.009 & 0.001 \\
$8: 2$ & 0.008 & 0.002 \\
$7: 3$ & 0.007 & 0.003 \\
$6: 4$ & 0.006 & 0.004 \\
$5: 5$ & 0.005 & 0.005 \\
$4: 6$ & 0.004 & 0.006 \\
$3: 7$ & 0.003 & 0.007 \\
$2: 8$ & 0.002 & 0.008 \\
$1: 9$ & 0.001 & 0.009 \\
$0: 10$ & 0 & 0.01 \\
\hline
\end{tabular}

\section{Finite Element Analysis of Weak Area Structure}

The three-dimensional discretization Hex finite element is used to mesh the weak area structure. In this paper, the strength of nine kinds of weak area structures are calculated under eleven ratio of bending-stretching coupling load. The parameters of weak area structure are presented by Table 4 .

Tab. 4 Different Parameters of Weak Aero Structure (mm)

\begin{tabular}{cccccccccc}
\hline Structure Parameters & $1 \#$ & $2 \#$ & $3 \#$ & $4 \#$ & $5 \#$ & $6 \#$ & $7 \#$ & $8 \#$ & $9 \#$ \\
\hline Length of Lapped & 5 & 5 & 5 & 7 & 7 & 7 & 9 & 9 & 9 \\
Thickness of Lapped & 0.1 & 0.2 & 0.4 & 0.1 & 0.2 & 0.4 & 0.1 & 0.2 & 0.4
\end{tabular}

The separated process of the glue line is very transient, so the pressure of the cover would not change in the process. The static finite element analysis method is used to calculate the strength of glue line of weak area structure, and structural strength can be expressed by tensile strain and shear strain. 
The strength of nine kinds of weak area structure is calculated under eleven ratio of bending-stretching coupling load, and the calculated results of weak area structure of parameter $l=5 \mathrm{~mm}, \mathrm{t}=0.1 \mathrm{~mm}$ are shown in Fig 4.

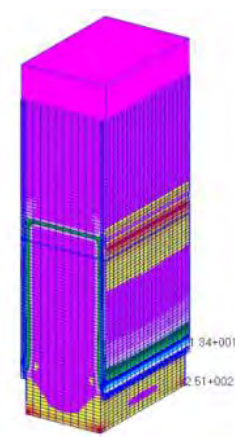

(a) $\mathrm{z}_{1}=0.01, \mathrm{x}_{1}=0$

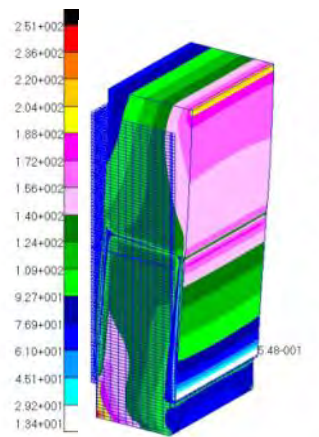

(b) $\mathrm{z}_{1}=0.006, \mathrm{x}_{1}=0.004$

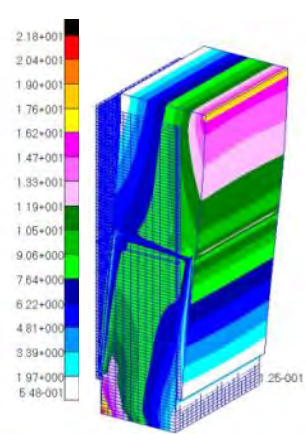

(c) $\mathrm{z}_{1}=0.004, \mathrm{x}_{1}=0.006$
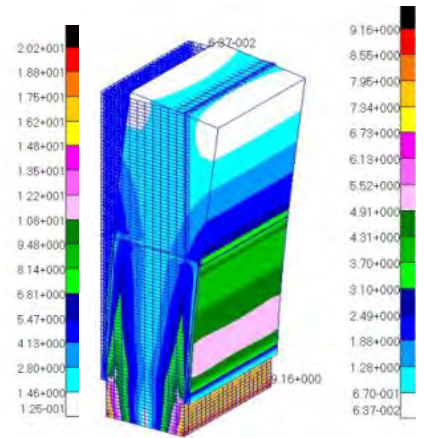

(d) $\mathrm{z}_{1}=0, \mathrm{x}_{1}=0.01$

Fig. 4 Cloud Picture of Stress in Different Load (mm)

\section{Finite Element Results}

The maximum stress value of weak area structure is reduced with the increase of the ratio of $\mathrm{X}$-direction displacement is increased. Without considering the stress value of loading surface and the clamped surface, the maximum stress value is close to lapped fiber layer which is between separated cover and framework. The elastic modulus of glue line is lower than the elastic modulus of other structures, so that the lapped fiber layer bears the most of tensile load. In a large proportion of the bending load conditions, the maximum stress value is on the bottom of both lapped fiber layers which are close to the framework, and with the X-direction displacement increasing, the absolute stress value of compressed lapped fiber layer is over the stress value subjected to tension lapped fiber layer.

The maximum principal stress rule is used to ensure the strength of glue line. Under the bending-stretching coupling load, the maximum stress is on the inside of glue line, so that the failure firstly appears at this place. The stress of the glue line achieves peak value, with the X-direction displacement increasing.

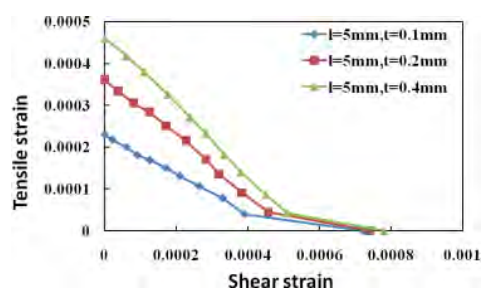

(a) $1=5 \mathrm{~mm}$

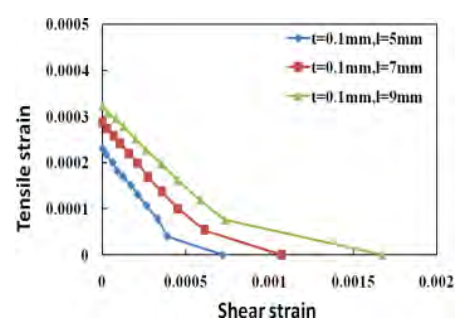

(d) $\mathrm{t}=0.1 \mathrm{~mm}$



(b) $1=7 \mathrm{~mm}$

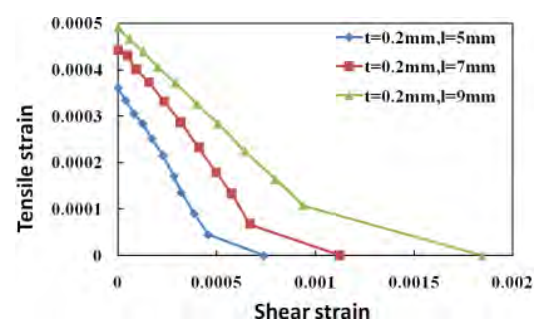

(e) $\mathrm{t}=0.2 \mathrm{~mm}$

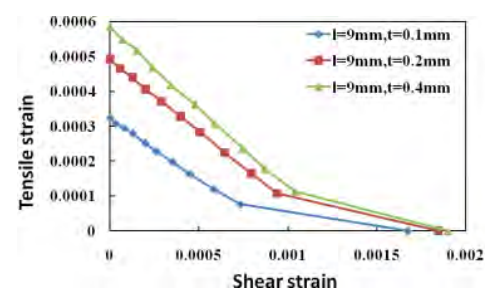

(c) $1=9 \mathrm{~mm}$

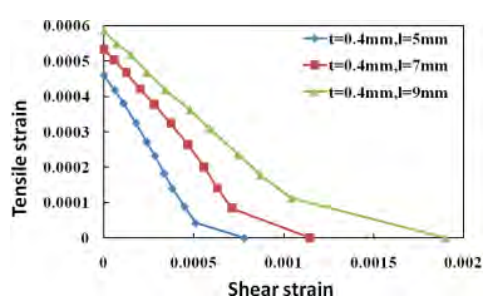

(f) $\mathrm{t}=0.4 \mathrm{~mm}$

Fig. 5 Strength Envelopes of Weak Aero Structure

Calculate the nine kinds of weak area structure under eleven different ratio of bending-stretching coupling load, and the results are shown in Fig 5.

When the thickness of lapped fiber layer is between $0.1 \mathrm{~mm}$ to $0.4 \mathrm{~mm}$, the strength of weak area structure increases with the development of length of lapped fiber layer, and increment of shear strain is higher than the increment of tensile strain. So affection the length of lapped fiber layer on the shear strain 
is greater than the tensile strain. Under the same condition of thickness, the increment of strength of the length increased to $7 \mathrm{~mm}$ from $5 \mathrm{~mm}$ is similar to the length increased to $9 \mathrm{~mm}$ from $7 \mathrm{~mm}$.

When the length of lapped fiber layer is between $5 \mathrm{~mm}-9 \mathrm{~mm}$, the strength of weak area structure increases with development of thickness of lapped fiber layer, and the tensile strain is affected greater by the thickness of lapped fiber layer than the shear strain. Under the same condition of length, the increment of strength of thickness increased to $0.2 \mathrm{~mm}$ from $0.1 \mathrm{~mm}$ is greater than the thickness increased to $0.4 \mathrm{~mm}$ from $0.2 \mathrm{~mm}$. So it can be summarized that the influence coefficient of strength is decreased when the thickness is greater than $0.2 \mathrm{~mm}$. Based on Fig 5, every line in that curves is more and more closed with the increment of X-direction displacement. That means that the thickness is more difficult to affect the strength of the weak area structure with the increment of the X-direction displacement.

According to the maximum principal rule, the strength of weak area structure can be calculated by the failure strain, and the strength curves are drawn under different ratio bending-stretching coupling load. The curves are shown in Fig 6.

Based on the curves, this strength of structure is different with different ratios of bending-stretching coupling load, because the length and thickness of lapped fiber layer can improve the strength in different degrees. In design process of circle composite fragile cover, the parameters of weak area structure can selected from the strength curves according to the strength of weak area structure which is needed by the cover. This design method can effectively reduce the repeated calculations and improve the design efficiency.

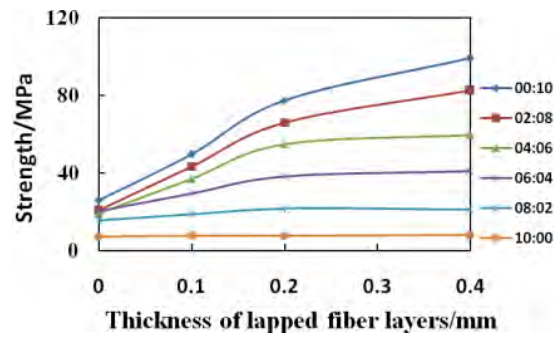

(a) $1=5 \mathrm{~mm}$

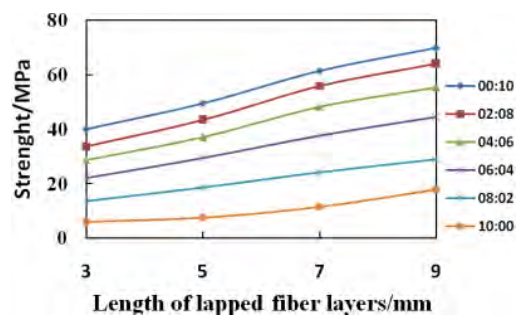

(d) $\mathrm{t}=0.1 \mathrm{~mm}$

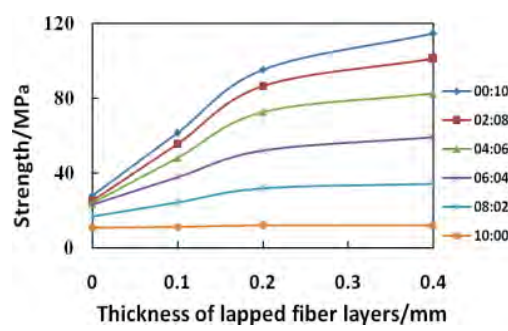

(b) $1=7 \mathrm{~mm}$

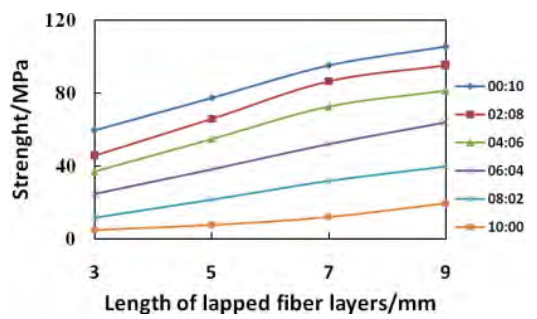

(e) $\mathrm{t}=0.2 \mathrm{~mm}$

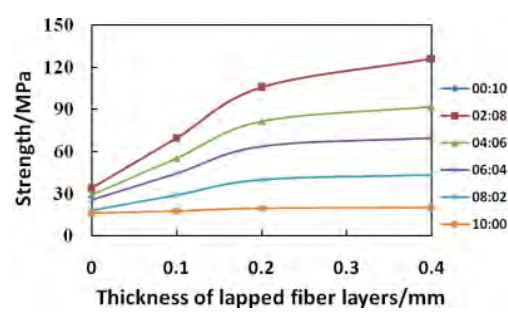

(c) $1=9 \mathrm{~mm}$

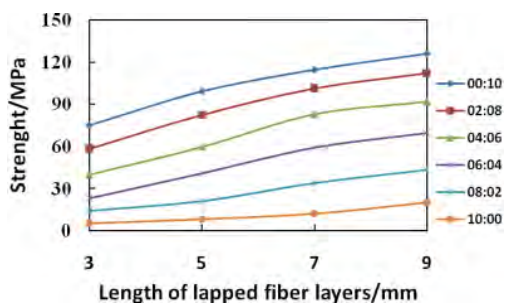

(f) $\mathrm{t}=0.4 \mathrm{~mm}$

Fig. 6 Strength Curves of Different Structural Parameters

\section{Experimental Studies}

\section{Experimental Method}

According to using demand, the parametric design method is used to design two kinds of cover which failure pressure is $0.06 \mathrm{MPa}$ and $0.10 \mathrm{MPa}$. Two kinds of cover have same shape, and the cover diameter is $100 \mathrm{~mm}$. The strength of two kinds of cover is $46 \mathrm{MPa}$ and $91 \mathrm{MPa}$ by finite element analysis. Based on Fig 6, the parameters of two kinds of weak area structure are ensured, and the ensured parameters are presented by Table 5. Six circle composite fragile covers were made which using same composite materials and ply way.

The experiment device consists of the launching tube, air pump, barometer and press ring. There is seal between launching tube and cover, the air pump injects air gas into the tube to make the fragile cover separate from framework. The experiment device and experiment pictures are shown in Fig 7.

Pump injects air gas into the launching tube with $0.01 \mathrm{MPa} / \mathrm{min}$, the failure pressure is read from press ring 


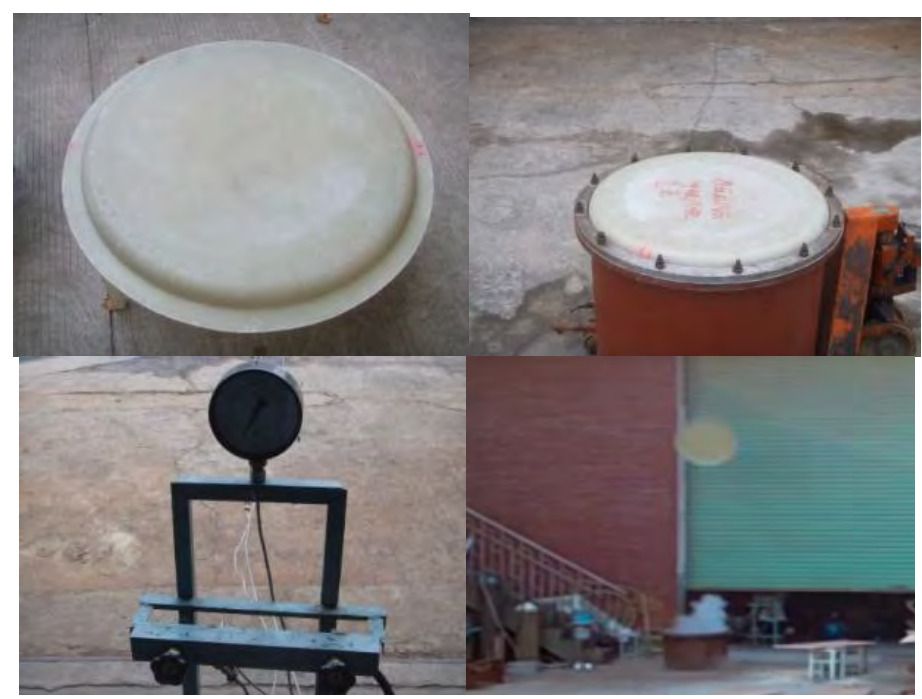

Fig. 7 Rush Experiment of Composite Fragile Cover

\section{Experimental Results}

Six circle composite fragile cover were rushed, and the experiment results are expressed by Table 6 . Based on Table 6, the failure strengths of weak area structure were stable, but the true failure pressure was lower than the design value. After analysis, two reasons are discovered. First, during the process of making circle composite fragile cover, there are some defects inside the weak area structure, but which defects are neglected when design the strength of weak area structure, and make the true strength lower than the design strength. Second, on the process of rush experiment, the true stress conditions are more complex than the design stress condition finite element calculation. The circumferential stress is not zero and it will be increased with the development of pressure, so that make the true strength lower than the design stress.

Tab. 5 Design Results of Weak Aero Structure

\begin{tabular}{|c|c|c|c|c|}
\hline $\begin{array}{l}\text { Design Failure } \\
\text { Pressure/MPa }\end{array}$ & $\begin{array}{c}\text { Strength of Weak Area } \\
\text { Structure/MPa }\end{array}$ & Length of Lapped/mm & $\begin{array}{l}\text { Thickness of } \\
\text { Lapped/mm }\end{array}$ & Numbers \\
\hline 0.06 & 46 & 7 & 0.1 & 3 \\
\hline 0.10 & 91 & 9 & 0.2 & 3 \\
\hline
\end{tabular}

Tab. 6 Experimental Results

\begin{tabular}{cccc}
\hline Number & Design Failure Pressure/MPa & True Failure Pressure/MPa & Error \\
\hline 1 & 0.06 & 0.052 & $10.0 \%$ \\
2 & 0.06 & 0.050 & $12.5 \%$ \\
3 & 0.06 & 0.053 & $8.8 \%$ \\
4 & 0.10 & 0.085 & $15.0 \%$ \\
5 & 0.10 & 0.090 & $10.0 \%$ \\
6 & 0.10 & 0.087 & $13.0 \%$ \\
\hline
\end{tabular}

\section{Conclusions}

(1) Calculated the strength of nine kinds of different parameters weak area structure under eleven different ratios of bending-stretching coupling load, the results show that the glue line between separate cover and framework bears the tensile load and the lapped fiber layer bears the bending load.

(2) Drawn the strength envelope curves, and then discussed the influence of parameters of weak area structure on the strength. The results show that the length of lapped fiber layer mainly affects the shear strength, the strength increments and the lapped length increments are liner relationship within the range of $5 \mathrm{~mm}-9 \mathrm{~mm}$. The tensile strengths are affected by the thickness of lapped fiber layer, and the strength 
increments within range of $0.1 \mathrm{~mm}-0.2 \mathrm{~mm}$ are bigger than the strength increments within $0.2 \mathrm{~mm}-0.4 \mathrm{~mm}$. So it can be ensured that the strength increments have limits with the development of thickness

(3) The relationship of strength with the parameters is established, then parametric design method is proposed, lastly this parametric design method is used to design and make 6 circle composite covers. According the rush experiments, the theoretical results are in close agreement with the experimental data and the mean error is about $11 \%$, which proves the feasibility of the proposed parametric design method

\section{Acknowledgement}

This research was financially supported by the Priority Academic Program Development of Jiangsu Higher Education Institutions, the Innovation Fund of Jiangsu Province on Industry-Academy-Research Cooperation (Grant No.BY2014003-10) and Foundation of Graduate Innovation Center in NUAA (kfjj130104).

\section{References}

[1]Copeland R L, Greene R F. Protective cover or a missile nose cone.US Pat.3970006, 1976.

[2]Boeglin P H. Plate-glass fitted with an explosion-cutting device. US Pat.4333381, 1982.

[3]Bell R E. Missile weapon system. US Pat.5239909, 1992.

[4]Krol U B. Frangible cover assembly for missile launchers. US Pat.3742814, 1971.

[5]Guiming S, Yu Z, Tingquan L. A Review and Prospect of Composite Design[J]. Journal of Solid Rocket Technology, 1997, 4: 010.

[6]Bai X, Ji A L, Cui H, et al. Effect of high temperature treatment on performances of needling carbon/carbon composite[J]. Journal of Solid Rocket Technology(JSRT), 2013, 36(1): 101-106.

[7]Xiao-jie W., LIANG Guo-zheng, ZHANG Wei, et al. Effects of hydrothermal aging on properties of high-performance composites [J]. Journal of Solid Rocket Technology, 2006, 29(3): 301-304.

[8]Kam T Y, Wu J H, Wang W T. External failure pressure of a frangible laminated composite canister cover[J]. Composite structures, 1999, 47(1): 563-569.

[9]Wu J H, Wang W T, Kam T Y. Failure analysis of a frangible laminated composite canister cover[J]. Proceedings of the Institution of Mechanical Engineers, Part G: Journal of Aerospace Engineering, 1999, 213(3): 187-195.

[10]Pickens J R, Tack W T .High strength Al-Cu-Lialloys for Lanch system [J]. NASA, Aluminum-Lithium Alloys for Aerospace Applications Workshop, 2004, 28(6): 58-64.

[11]ZHOU G, YUAN Z. Design, Manufacture and Experiment for New-Style Composite Frangible Fly Through Diaphragm Cover [J]. Journal of Astronautics, 2006, 2: 025.

[12]ZHOU G, YUAN Z, WANG X. Study of Design and Experiment for Integrated Frangible Composite Diaphragm Cover [J]. Journal of Astronautics, 2007, 3: 039.

[13]SHEN G L, HU G K. Mechanics of composite materials [M]. Tsinghua University Press, 991: 69-71. 